\title{
Rancang Bangun Prototipe Wahana Bawah Air Tipe Working Class ROV (Remote Operating Vehicle)
}

\author{
${ }^{1}$ Aditya Ramanda*), 2Indra Jaya, 2Sri Pujiyati, ${ }^{2}$ Muhammad Iqbal \\ 1Program Studi IImu dan Teknologi Kelautan Program Sarjana IPB \\ 2Departemen IImu dan Teknologi Kelautan FPIK IPB Kampus IPB Dramaga Bogor
}

aditya_itk48@yahoo.co.id*)

\begin{abstract}
Abstrak
ROV adalah sebuah robot bawah laut yang dikendalikan oleh operator ROV untuk pekerjaan di bawah air. ROV terbagi menjadi lima kelas yaitu: Pure Observation, Observation With Payload Option, Work Class Vehicles, Seabed-Working Class, dan Prototype or Development Vehicles. Dalam penelitian ROV telah dikembangkan RJBA V.2015 dengan penambahan manipulator, sensor dan perbaikan sistem olah gerak robot. Tujuan dari penelitian adalah mengembangkan robot jelajah bawah air sehingga dapat melakukan fungsinya dalam hal eksplorasi bawah laut. Tahapan penelitian terdiri dari rancang bangun RJBA V.2015, elektronika, program kendali, dan mekanika. RJBA V.2015 ini memiliki berat $\pm 18 \mathrm{~kg}$ dengan dimensi $107 \mathrm{~cm} \times 35 \mathrm{~cm} \times 20 \mathrm{~cm}$. Robot ini memiliki manipulator dengan bukaan maksimal 10 cm, 4 motor penggerak, sensor 10 DOF dan dihubungkan dengan kabel sepanjang 15 meter. Robot ini termasuk kedalam kategori III A Work Class Vehicles. RJBA V.2015 mampu melakukan pergerakan secara horizontal dan vertikal dengan baik. Manipulator RJBA V.2015 dibuat sederhana, mampu bergerak terhadap sumbu X, Y, Z serta mampu mencapit dengan baik.

Kata kunci: ROV, RJBA V.2015, Sensor, Pergerakan, Manipulator.
\end{abstract}

\section{Pendahuluan}

\subsection{Latar Belakang}

Perkembangan ilmu pengetahuan dan teknologi dunia berkembang sangat pesat, salah satu pengembangan adalah teknologi jelajah bawah air. Indonesia sebagai Negara kepulauan dengan luas laut mencapai 5,8 juta $\mathrm{km}^{2}$ sudah sepatutnya ikut andil dalam pengembangan teknologi bawah air. Bentuk dari pengembangan teknologi bawah air adalah terciptanya Remotely Operated Vehicle (ROV). ROV adalah sebuah robot bawah laut yang dikendalikan oleh operator ROV, yang digunakan untuk pekerjaan di lingkungan yang berbahaya terutama laut dalam [1]. ROV sekarang menjadi sebuah alat yang sangat penting untuk mengeksplorasi dan mengeksploitasi kondisi lingkungan bawah air karena mampu melakukan pekerjaan yang bersifat tehnik di bawah air [2].

Menurut Woods [3], ROV memiliki peran dalam hal observasi bawah air terutama dalam observasi fasilitas produksi minyak sekaligus menggantikan tugas dari penyelam yang memiliki keterbatasan.
ROV juga dapat digunakan untuk pemetaan dan monitoring terumbu karang, pengamatan dan instalasi kabel bawah air, eksplorasi dan observasi laut dalam, dan berbagai tugas lainnya sesuai kemampuan robot bawah air. ROV memiliki fungsi masing-masing dari wahana bawah air berdasarkan kelasnya. Menurut NTC (Norwegian Technology Center) [4], RJBA terbagi menjadi lima kelas yaitu: Pure Observation, Observation With Payload Option, Work Class Vehicles, Seabed-Working Class, dan Prototype or Development Vehicles. Semakin berkembangnya teknologi, ROV terus dikembangkan kemampuannya untuk dapat melakukan berbagai hal di bawah air [5]. Menurut NOAA [6], kemampuan ROV dapat ditingkatkan dengan menambahkan beberapa instrumen seperti manipulator, water sampler, dan Conductivity, Temperature and Depth.

Rancang bangun atau desain bangunan adalah suatu proses perancangan yang menggambarkan sistematika suatu bangunan. Rancang bangun bertujuan untuk mempermudah dalam pembuatan suatu bangunan. Rancang bangun pada penelitian ini berupa perancangan lengan manipulator dan perancangan Robot Jelajah Bawah Air (RJBA). Lengan manipulator merupakan robot berbentuk lengan yang berfungsi untuk memanipulasi (memegang, mangambil, mengangkat, memindahkan) obyek. Menurut Ahadyat [7] manipulator lengan merupakan sebuah perangkat mekanik yang berbentuk dan berfungsi menyerupai lengan manusia.

Pengembangan RJBA di Indonesia tidak terlalu maju dibanding negara lain. Indonesia sebagai negara kepulauan sangat membutuhkan sebuah RJBA, namun RJBA yang digunakan merupakan produk dari negara lain bukan ciptaan Indonesia. Di Indonesia RJBA masih dalam pengembangan oleh institusi di bidang teknologi khususnya teknologi kelautan. Di Institut Pertanian Bogor yang diwakilkan oleh Departemen IImu dan Teknologi Kelautan telah mengembangkan robot bawah air. Beberapa penelitian mengenai RJBA yang telah dilakukan oleh Kusuma [8] dan Putra [9] namun masih belum mencapai kesempurnaan dalam hal olah gerak, dan perangkat tambahan seperti sensor. Mengingat fungsi dan manfaat robot bawah 
air di bidang kelautan, maka perlu dilakukan penelitian lanjutan mengenai robot bawah air.

\subsection{Metode}

\subsubsection{Rancang Bangun RJBA V.2015}

Penelitian sebelumnya yang dilakukan oleh Putra [9] memiliki beberapa saran di antaranya : penyempurnaan sistem Ballast dan penambahan sensor navigasi seperti sensor tekanan, kedalaman, dan sensor lainnya. Menindaklanjuti saran dari penelitian sebelumnya, pengembangan yang akan dilakukan pada RJBA versi 2015 (RJBA V.2015) ini adalah perancangan manipulator, penambahan sensor tekanan, sensor suhu, dan sensor 10 DOF. Perancangan robot jelajah bawah air ini terbagi menjadi 4 bagian, yaitu bagian desain, bagian programming, bagian elektronik, dan bagian mekanik. Diagram alir penelitian tertera pada Gambar 1.

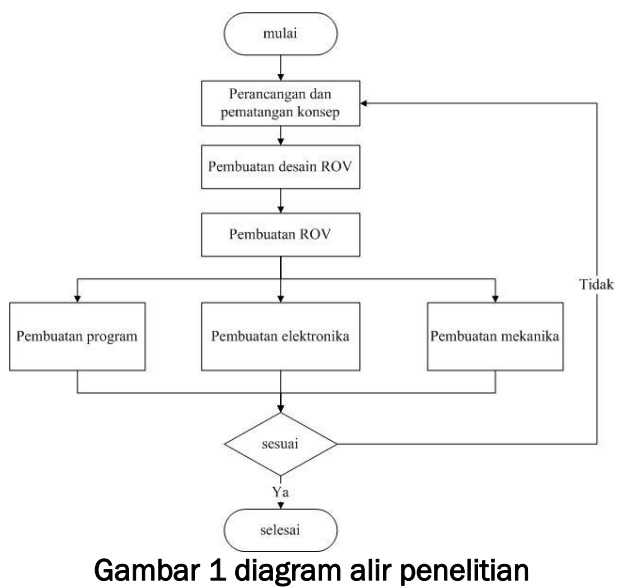

\subsubsection{Rancang Bangun Desain}

Pembuatan desain merupakan tahap awal dalam pembuatan RJBA V.2015. Tahap ini merupakan tahap pemantapan konsep dan pengembangan konsep dari pembuatan RJBA V.2015. Dalam penelitian ini RJBA V.2015 yang dibuat bertujuan untuk melakukan observasi bawah air. Untuk menjalan tugas tersebut, RJBA V.2015 ini dilengkapi cctv sebagai kamera untuk melakukan observasi. Selain itu untuk memudahkan RJBA V.2015 untuk melakukan manuver, RJBA V.2015 ini dilengkapi 4 buah motor penggerak. RJBA V.2015 yang akan dibuat juga dilengkapi dengan manipulator yang berguna pada saat pengambilan sampel atau objek di bawah air. Gambar RJBA V.2015 secara 3 dimensi yang ditunjukkan pada Gambar 2.

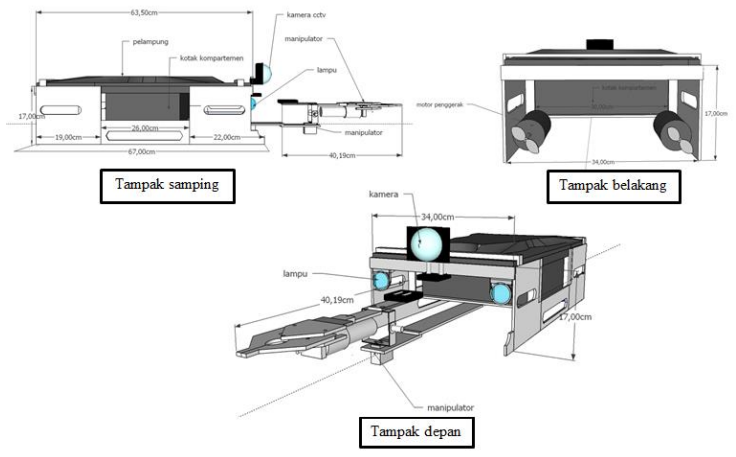

Gambar 2 model rjba v.2015

\subsubsection{Rancang Bangun Program}

Bagian ini merupakan tahap pembuatan perintah kerja yang dipasang pada Arduino Mega 2560. Gambar 3 menunjukkan Diagram Alir Program. Perangkat lunak yang digunakan adalah Arduino dan Microsoft Visual Studio. Pada Arduino menggunakan bahasa pemrograman $\mathrm{C}++$ sedangkan Microsoft Visual Studio menggunakan bahasa pemrograman C\#. Arduino yang digunakan adalah versi 1.0.6, yang berfungsi untuk memprogram sensor, motor brushless, motor DC, dan motor servo. Microsoft Visual studio berfungsi untuk membuat GUI (Guide User Interface).

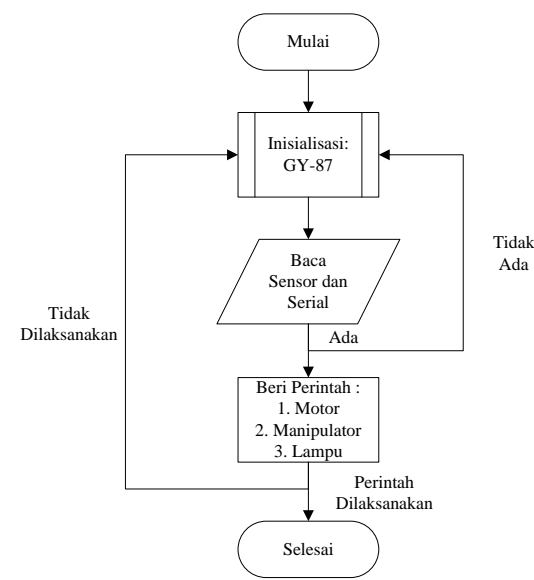

Gambar 3 diagram alir program rjba v.2015

\subsubsection{Rancang Bangun Elektronika}

Pada bagian ini merupakan tahap perakitan komponen dari RJBA V.2015. Tahap ini dilakukan dengan menghubungkan komponen-komponen elektronika seperti Arduino Mega, Kamera, Sensor, Motor Brushless, dan komponen lainnya. Di bawah ini merupakan skematik rancangan elektronika yang ditunjukkan pada Gambar 4. 


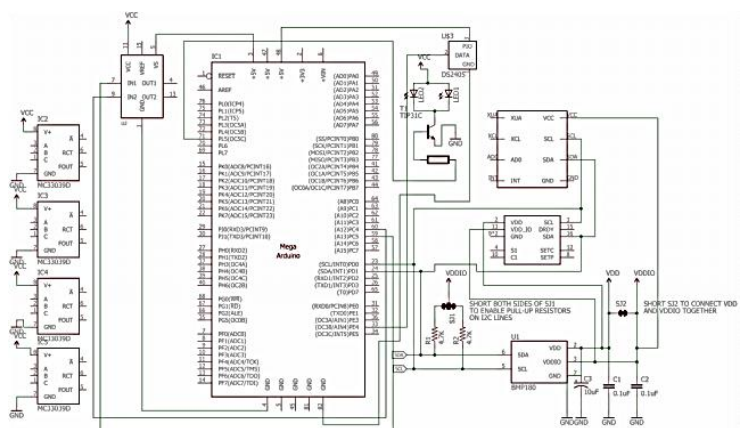

Gambar 4 skematik rancangan elektronika

Komponen elektronik yang telah tersusun secara skematik akan berfungsi sesuai kegunaannya. Komponen elektronik memiliki hubungan fungsional antar komponen, baik berupa data dan tegangan. Hubungan antar tegangan bersumber dari accu dan hubungan antar data berpusat di Arduino Mega. Accu akan memberikan tegangan untuk menyalakan semua komponen, Arduino Mega akan mengirimkan sinyal perintah, sinyal perintah yang diterima akan dijalankan oleh setiap komponen. Adapun hubungan fungsional antara semua bagian elektronika dapat dilihat pada Gambar 5.

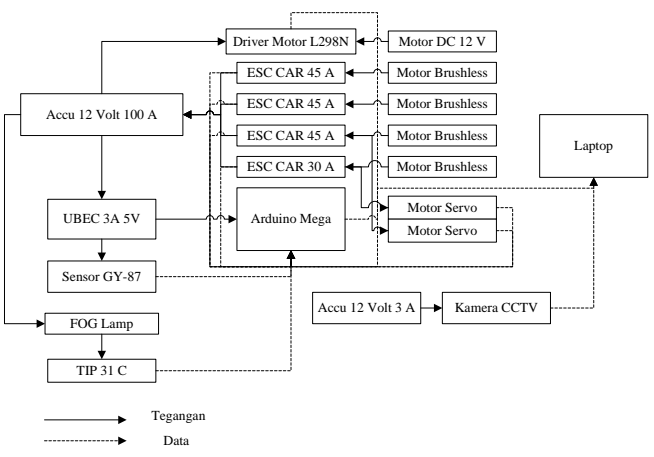

Gambar 5 hubungan fungsional elektronika

\subsubsection{Rancang Bangun Mekanika}

Bagian ini berkaitan dalam pembentukan fisik dari RJBA V.2015. Pembentukan fisik RJBA V.2015 terdiri dari pembuatan frame, box kompartemen, manipulator, penempatan motor, body RJBA V.2015, dan hal lainnya yang berhubungan dengan bentuk fisik RJBA V.2015. Frame dibuat menggunakan bahan dari plat alumunium $5 \mathrm{~mm}$. Manipulator dibuat menggunakan plat alumunium $5 \mathrm{~mm}$. Body RJBA V.2015 dibuat menggunakan polyurethane yang nantinya dilapisi oleh resin, sedangkan box kompertemen menggunakan resin.

\subsubsection{Uji Coba RJBA V.2015}

Uji coba RJBA V.2015 dilakukan di Watertank laboraturium Akustik dan Instrumentasi Kelautan dan di kolam renang Babakan lio. Uji coba di watertank ditujukan untuk melihat buoyancy robot dan fungsi dari komponen-komponen robot. Uji coba lab menunjukkan bahwa semua komponen sudah berfungsi dengan baik namun robot tidak mampu masuk ke dalam air yang dikarenakan gaya apung robot lebih besar. Menindaklanjuti permasalahan gaya apung, maka RJBA V.2015 diberi beban agar mampu melayang di bawah air. Informasi tambahan mengenai uji coba lab dapat dilihat pada Lampiran 1 dan 2. Uji coba di Kolam Babakan lio ditujukan untuk melihat manuver dan kestabilan dari RJBA V.2015. Uji coba kolam menunjukkan RJBA V.2015 memiliki kestabilan yang baik serta mampu melakukan manuver dengan baik. RJBA ini dapat diaplikasikan pada perairan tenang seperti danau.

\section{Diskusi}

Hasil dari penelitian ini berupa Robot Jelajah Bawah Air V. 2015 dengan panjang $107 \mathrm{~cm}$, lebar $35 \mathrm{~cm}$, tinggi $20 \mathrm{~cm}$, dan berat total $\pm 18 \mathrm{~kg}$. Robot ini dilengkapi manipulator, 4 thruster sebagai penggerak, lampu, kamera cctv, dan sensor-sensor tambahan. RJBA V.2015 menggunakan 4 buah thruster yang bertujuan agar robot dapat melakukan pergerakan dasar yaitu maju, mundur, belok kanan, belok kiri, naik, dan turun. Kamera yang digunakan pada RJBA V.2015 memiliki resolusi sebesar 976 × 582 pixel. Robot ini menggunakan kabel sepanjang 15 meter untuk komunikasi serial dengan kendali di permukaan menggunakan laptop. Menurut Newman dan Robinson [10] kabel yang digunakan haruslah bersifat tahan lama dan memiliki kualitas yang baik agar mengurangi gangguan proses komunikasi serial. RJBA V.2015 ini dapat diklasifikasikan ke dalam kelas III A Work class vehicles dan kelas V Prototype or Development Vehicles [4]. Work class vehicles III A yaitu wahana mampu membawa sensor tambahan dan manipulator tanpa mengganggu sistem pusat dengan kemampuan di bawah 100 Horse Power. Gambar 6 menunjukkan RJBA V.2015.

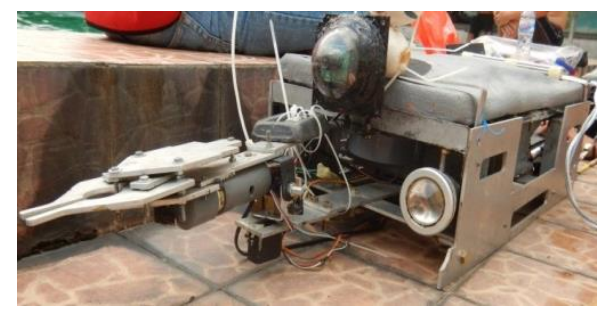

Gambar 6 rjba v.2015

\subsubsection{Bagian Desain RJBA V.2015}

Robot jelajah bawah air yang dikembangkan kali ini merupakan pengembangan dari desain dari RJBA 
V.2014, yang mana robot ini memiliki pelampung berbentuk persegi panjang dengan dimensi pelampung $65 \mathrm{~cm} \times 35 \mathrm{~cm}$. Bentuk persegi panjang bertujuan untuk memudahkan titik berat robot dan tata letak komponen dengan tepat agar memiliki keseimbangan yang baik ketika beroperasi di dalam air [9]. Pelampung yang terdapat pada RJBA V.2015 berfungsi sebagai pelampung dan menjaga keseimbangan robot. Pada RJBA V.2015 didesain untuk memiliki kotak kompartemen sendiri, yang mana kotak kompartemen tidak menyatu dengan pelampung. Hal tersebut dilakukan agar kompartemen tidak mengalami gangguan jika terjadi kebocoran pada pelampung dan hal tersebut tidak dimiliki pada generasi sebelumnya.

\subsubsection{Bagian Mekanika RJBA V.2015}

Bagian mekanika merupakan pembahasan mengenai bentuk fisik dari RJBA yang telah dibuat. Pembuatan bagian mekanika pada RJBA V.2015 terbagi menjadi: rangka, box kompartemen, pelampung (body RJBA V.2015), dan manipulator. Secara fisik RJBA V.2015 dibuat menggunakan plat alumunium, Polyurethane dan resin.

Kerangka fisik RJBA V.2015 yang terdiri dari kerangka luar (frame), kotak kompartemen, dan pelampung (body RJBA V.2015). Kerangka luar (frame) dibuat dengan menggunakan plat alumunium dengan ketebalan $5 \mathrm{~mm}$. Penggunaan plat alumunium dikarenakan memiliki daya tahan yang kuat dan tidak mudah korosi. Plat alumunium juga digunakan dalam pembuatan manipulator. Kotak kompartemen yang digunakan terbuat dari resin dengan ketebalan mencapai $2 \mathrm{~cm}$ dan dilengkapi dengan karet yang berfungsi untuk menahan masuknya air ke kotak kompartemen. Pelampung atau body RJBA V.2015 terbuat dari polyurethane yang kemudian dilapisi resin. Penggunaan polyurethane dikarenakan mudah dibentuk sesuai keinginan dan pelapis resin bertujuan untuk memperkokoh pelampung. Kotak kompartemen diletakkan di bawah pelampung. kotak kompartemen dibuat kedap udara, hal ini dilakukan dengan cara menekan karet menggunakan akrilik sebagai penutup, kemudian di baut agar dapat tertekan dengan kuat. Manipulator (Gambar 7) terbuat dari plat alumunium $5 \mathrm{~mm}$ yang disusun menyerupai penjepit. Manipulator ditujukan untuk menjepit objek.

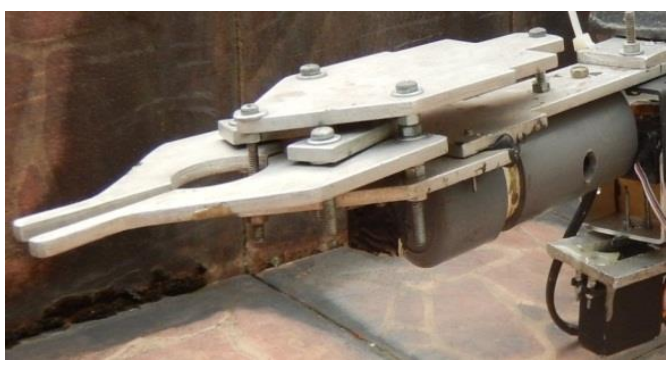

Gambar 7 manipulator

\subsubsection{Sistem Elektronik RJBA V.2015}

Sistem elektronik merupakan rangkaian dari komponen-komponen yang saling terhubung sesuai dengan fungsi dan tujuannya. Pada RJBA V.2015 dilengkapi dengan komponen-komponen berupa Arduino Mega, Accu $12 \mathrm{~V}$, kamera CCTV, Underwater lamp, motor servo, dan sensor tambahan. Arduino Mega digunakan sebagai pengendali utama dari semua komponen, yang nantinya akan ditampilkan pada interface.

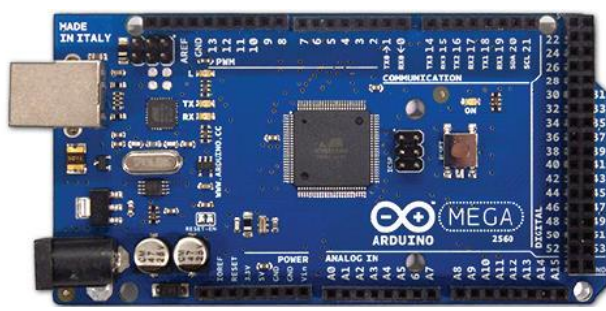

Gambar 8 arduino mega 2560

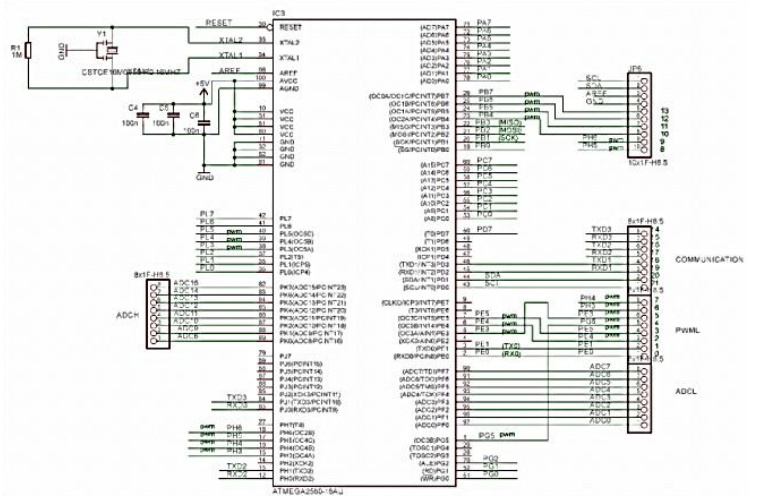

Gambar 9 rangkaian elektronik arduino mega 2560

Gambar 8 menunjukkan bentuk dari Arduino Mega 2560 yang digunakan pada RJBA V.2015 dan Gambar 9 menunjukkan rangkaian elektronik dari Arduino Mega. Arduino Mega 2560 adalah papan mikrokontroler berbasiskan ATmega2560. Arduino Mega 2560 memiliki 54 pin yang dapat digunakan sebagai input dan output. Arduino Mega juga dilengkapi kristal eksternal $16 \mathrm{MHz}$ yang memungkinkan proses instruksi perintah berjalan dengan cepat [11]. 


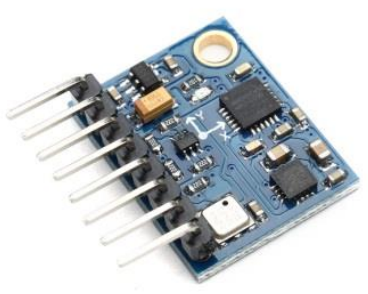

Gambar 10 sensor gy-87

Gambar 10 menunjukkan sensor Gy-87 yang merupakan sensor tambahan yang terdapat pada RJBA V.2015. Gy-87 merupakan sensor 10 DOF yang terdiri dari 3 axis Gyro, 3 axis Acceleration, 3 axis Magnetic Field dan Air Pressure Module. Gy-87 adalah gabungan dari MPU-6050, HMC5883L, dan BMP180. MPU-6050 adalah sebuah sensor yang terdiri dari MEMS Accelerometer dan sebuah MEMS Gyro yang saling terintegrasi. Sensor ini sangat akurat dengan fasilitas hardware internal 16 bit ADC untuk setiap kanalnya. Sensor ini akan menangkap nilai kanal axis $\mathrm{X}, \mathrm{Y}$ dan $\mathrm{Z}$ bersamaan dalam satu waktu. Gambar 11 menunjukkan rangkaian utama MPU-6050.

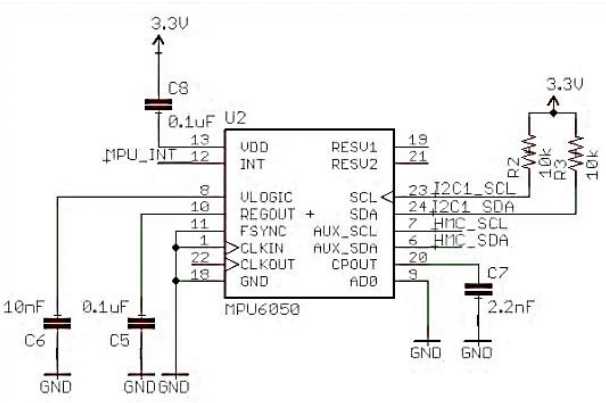

Gambar 11 rangkaian mpu-6050

HMC5883L adalah sensor magnet yang tersusun atas sensor resistif magnet beresolusi tinggi dengan demagnetisasi otomatis, penghilang offset dan ADC 12-bit untuk pengukuran medan magnet bumi dengan resolusi tinggi. Menggunakan teknologi anisotropic magneto-resistive (AMR) Honeywell. HMC5883L menyediakan kepresisian lebih pada sensitifitas dan linieritas sumbu dan dirancang untuk mengukur kedua arah dan medan magnet bumi. Gambar 12 menunjukkan rangkaian dari HMC5883L.

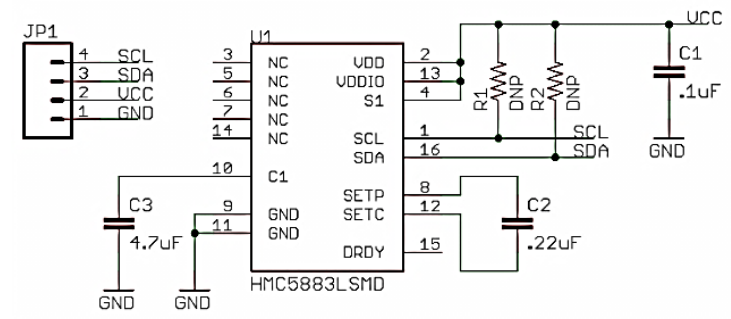

Gambar 12 rangkaian hmc5883।

BMP180 adalah sensor tekanan barometrik (digital barometric pressure sensor) dari Bosch Sensortec yang berkinerja sangat tinggi yang dapat diaplikasikan pada berbagai perangkat bergerak. Sensor ini menghasilkan data tekanan. Data tekanan yang diperoleh akan dikonversikan menjadi data kedalaman, yang digunakan untuk mengetahui kedalaman yang ditempuh oleh RJBA V.2015. Gambar 13 menunjukkan rangkaian dari BMP180.

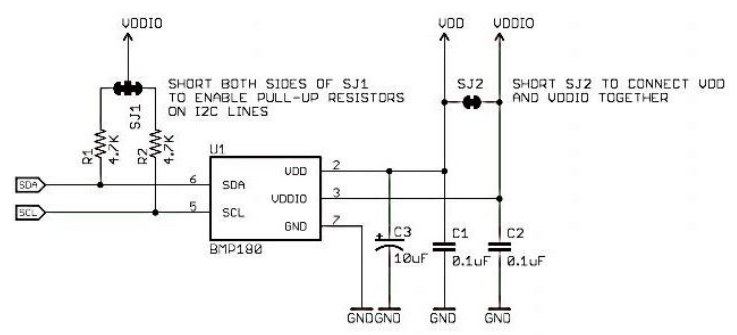

Gambar 13 rangkaian bmp180

\subsubsection{Program Utama RJBA V.2015}

Robot Jelajah Bawah Air menggunakan mikrokontroller Arduino Mega sebagai pusat pengolahan sistem kendali terhadap robot. Bahasa pemrograman yang digunakan adalah bahasa $\mathrm{C}$ Arduino dan Bahasa C\# pada Visual Studio. Adanya pemrograman sangat penting, menurut Idris [12] mikrokontroler tidak dapat bekerja tanpa adanya perangkat lunak atau program yang tertanam di dalamnya. Program yang tertanam pada mikrokontroler dibuat untuk dapat mengatur pergerakan robot, mengatur manipulator, menerima data sensor, serta mengirim data ke interface pada laptop. Menurut Olejnik [13], tampilan observasi secara langsung dari ROV akan membantu untuk mengidentifikasi objek di bawah laut. Interface yang terdapat pada laptop dibuat dengan menggunakan bahasa C\# pada Microsoft Visual Studio. Gambar 14 menunjukkan interface RJBA V.2015 pada laptop. 


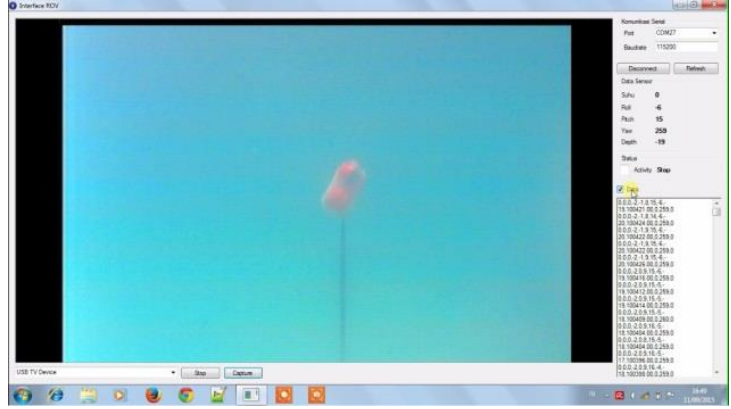

Gambar 14 interface rjba v.2015

Interface memuat gambar hasil dari kamera CCTV, dan data sensor. Gambar berwarna merah pada interface merupakan gambar dua bola yang dijadikan sebagai objek di bawah air. Data sensor yang ditampilkan adalah roll, pitch, yaw, dan depth. Data roll menunjukkan kemiringan robot terhadap sumbu $x$ (berguling). Data pitch menunjukkan kemiringan robot terhadap sumbu y (mengangguk). Data yaw pada interface menunjukkan data kompas, yang bertujuan untuk mengetahui ke arah mana robot menghadap menurut mata angin dalam satuan derajat. Robot ini memiliki kestabilan yang baik dengan di kedalam 3 meter, dengan keadaan rolling, pitching, dan yawing yang stabil. Nilai rolling berkisar 0 sampai 10 derajat, pitching 0 sampai 30 derajat, dan yawing bernilai sesuai arah kompas. Nilai pitching yang mencapai 30 derajat dikarenakan penambahan manipulator pada bagian depan, sehingga bagian depan robot lebih berat. Data Kedalaman pada interface belum menunjukkan data sesungguhnya sehingga perlu adanya kalibrasi dan penambahan formula agar mendapat nilai yang sesunggunya. Data kedalaman yang diinginkan juga dapat diperoleh dengan menggunakan sensor yang lebih baik atau penambahan sistem sonar pada robot. Kolom status pada interface menunjukkan kegiatan yang sedang dilakukan oleh robot. Kolom status juga digunakan untuk memberi perintah kepada RJBA V.2015. perintah yang diberikan dapat berupa mengetik ' $L$ ' maka lampu akan menyala, mengetik 'shift' maka robot akan naik, mengetik 'ctrl' maka robot akan turun, mengetik ' $\rightarrow$ 'dan' $\leftarrow$ ' maka robot akan berbelok kanan dan kiri, mengetik 'j' dan 'k' maka manipulator akan bergerak kanan dan kiri.

\subsubsection{Olah Gerak RJBA V.2015}

Robot Jelajah Bawah Air adalah robot yang mampu melakukan tugas di dalam air dengan kendali dari permukaan. RJBA V.2015 dapat melakukan tugasnya robot ini harus mampu melakukan olah gerak yang baik. Robot ini dilengkapi dengan 4 buah motor penggerak, yang terdiri dari 2 motor untuk pergerakan secara horizontal dan 2 motor untuk pergerakan secar vertikal. RJBA V.2015 ini memiliki perbedaan pada penggunaan motor dengan generasi sebelumnya. RJBA V.2015 menggunakan motor brushless dengan kekuatan 1060 kv dan dilengkapi propeller 2 daun berbahan alumunium. Propeller diperuntukkan mengarahi aliran fluida yang berguna untuk menjalankan RJBA. Menurut Christ dan Wernli [14], baling-baling didesain untuk bergerak dan mengarahkan fluida berlawanan dengan arah gerak. Menurut Ismail [15], semakin sedikit jumlah daun propeller, maka efisiensi propeller semakin tinggi, namun masingmasing daun akan menanggung beban yang lebih besar.

Penggunaan motor brushless dikarenakan motor jenis ini memiliki ukuran yang lebih kecil dan lebih mudah mengatur kecepatan motor dibandingkan pada generasi sebelumnya. 2 motor penggerak vertikal diletakkan di depan dan di belakang dengan posisi berada di tengah, sedangkan 2 motor penggerak horizontal diletakkan di belakang dengan posisi berada di kiri dan kanan. Motor penggerak pertama berada di depan, kedua di belakang, motor penggerak ketiga dan keempat berada di belakang kiri dan kanan. Tabel 4 merupakan olah gerak robot berdasarkan ujicoba kolam. Gambar 15 dan 16 menunjukkan Pola pergerakan dari Robot.

Table 1 olah gerak rjba v.2015 berdasarkan tata letak dan arah putaran

\begin{tabular}{|c|c|c|c|c|}
\hline T1 & T2 & T3 & T4 & $\begin{array}{c}\text { Performa } \\
\text { RJBA V.2015 }\end{array}$ \\
\hline CW & CW & - & - & $\begin{array}{l}\text { Bergerak } \\
\text { Turun }\end{array}$ \\
\hline CCW & CCW & - & - & Bergerak Naik \\
\hline- & - & CW & CW & Maju Kedepan \\
\hline - & - & CCW & CCW & Mundur \\
\hline - & - & CW & CCW & Maju kekanan \\
\hline - & - & CCW & CW & Maju Kekiri \\
\hline \multicolumn{5}{|c|}{$\begin{array}{l}\text { keterangan : } \mathrm{T}=\text { Thruster, } \mathrm{CW}=\text { Clockwise, } \mathrm{CCW}=\text { Counter } \\
\text { Clockwise }\end{array}$} \\
\hline
\end{tabular}

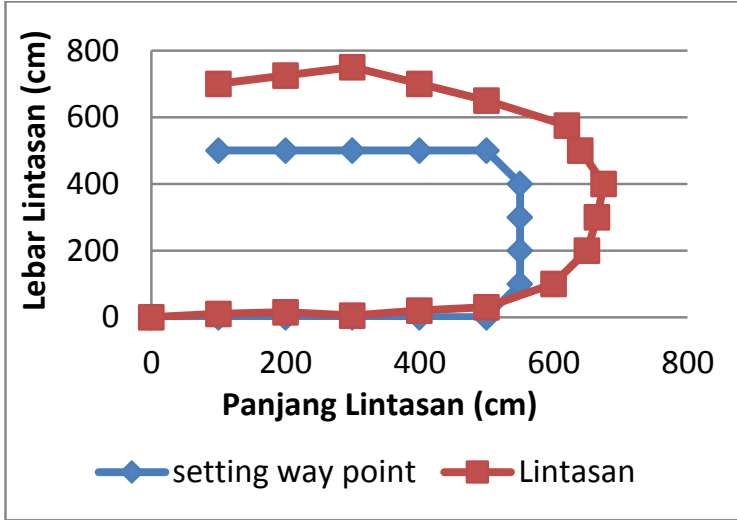

Gambar 15 pergerakan robot secara horizontal 


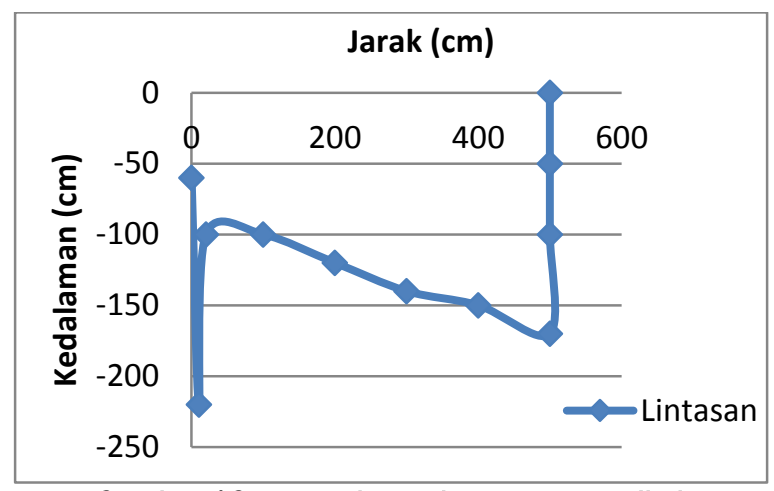

Gambar 16 pergerakan robot secara vertikal

Robot ini dapat melakukan pergerakan dengan baik seperti yang terlihat pada Gambar 10 dan 11. Pada Gambar 15 robot dapat bergerak maju dengan baik, namun robot masih memiliki kekurangan dalam berbelok. Pada pergerakan berbelok robot tidak dapat berbelok patah, sehingga mengharuskan robot mengambil jarak yg cukup jauh. Hal tersebut dikarenakan penempatan motor penggerak belakang kiri dan kanan yang tidak baik. Motor penggerak belakang berada di belakang kotak kompartemen, sehingga aliran air yang datang hanya dari belakang dan samping motor. Hal tersebut menyebabkan kemampuan RJBA V.2015 dalam melaju dan mundur berbeda. Penempatan motor penggerak baiknya diletakkan pada ruang terbuka. Pada Gambar 16 terlihat bahwa RJBA V.2015 langsung berada pada posisi melayang pada kedalaman $60 \mathrm{~cm}$. Hal tersebut dikarenakan RJBA V.2015 dirancang untuk langsung melayang di kolom perairan. Robot dibantu oleh motor penggerak untuk dapat melakukan manuver secara vertikal dan horizontal.

\subsubsection{Sistem Kerja Manipulator RJBA V.2015}

Pada pengembangan robot jelajah bawah air kali ini dilengkapi dengan manipulator atau tangan penjepit. Menurut [16], robot bawah air biasanya dilengkapi satu atau beberapa gripper/manipulator untuk dapat melakukan tugas-tugas di dalam air. Manipulator robot terbuat dari bahan dasar alumunium dengan ketebalan $5 \mathrm{~mm}$. Pergerakan manipulator didukung dengan adanya 2 buah servo untuk bergerak secara horizontal dan vertikal. RJBA V.2015 dapat membuka dan menutup pencapit, manipulator menggunakan motor dc. Manipulator RJBA V.2015 dapat bergerak dengan bukaan maksimal $10 \mathrm{~cm}$. Manipulator digerakkan dengan menggunakan keyboard pada laptop pada interface robot. Perintah yang dikirim dari interface akan diterima oleh Arduino Mega, kemudian Arduino Mega akan memberikan perintah kepada motor servo dan motor dc untuk bergerak sesuai perintah yang dikirimkan. Berdasarkan uji coba manipulator yang dibuat memiliki kemampuan maksimal mengangkat beban botol mineral $600 \mathrm{ml}$ yang terisi penuh dengan daya cengkram yang baik dan lebar maksimal beban mencapai $8 \mathrm{~cm}$. Manipulator pada RJBA V.2015 didesain sederhana. Menurut Christ dan Wernli [17] Ketika memilih manipulator, penting untuk memilih jenis yang mungkin paling sederhana yang dapat menyelesaikan tugas dalam waktu yang wajar. Gambar 17 menunjukkan pola pergerakan dari manipulator.

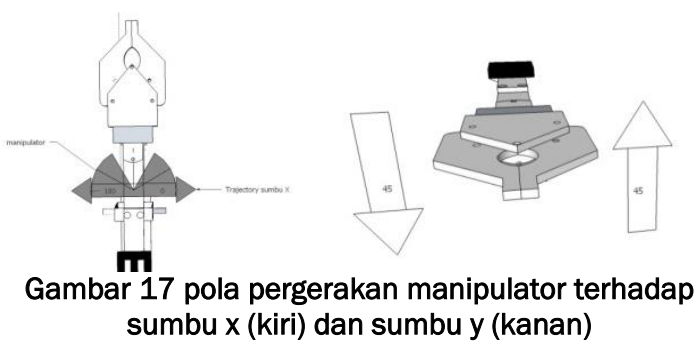

Pola pergerakan pada sumbu $\mathrm{x}$ berkisar $0^{\circ}$ sampai $180^{\circ}$ dan pergerakan pada sumbu y berkisar $0^{\circ}$ sampai $90^{\circ}$. Hal tersebut berarti manipulator mampu bergerak ke kanan dan kiri dengan sudut maksimal $180^{\circ}$ dan bergerak mengangguk ke atas dan bawah dengan sudut maksimal $90^{\circ}$. Pergerakan dari manipulator sudah cukup baik karena sudah dapat bergerak tehadap sumbu X, Y dan Z. Menurut Haugen [16] bila tidak ada gaya kontrol yang diterapkan untuk model dinamis, model manipulator diharapkan untuk berperilaku seperti multi sendi, bergerak terhadap sumbu $X, Y$ dan Z.

\section{Kesimpulan}

Robot Jelajah Bawah Air V. 2015 telah berhasil dibuat dan dilengkapi manipulator, sensor GY-87, lampu, motor penggerak, dan kamera CCTV untuk dapat melakukan tugas di bawah air. Robot ini dibuat dari bahan plat alumunium $5 \mathrm{~mm}$, resin, dan Polyurethane. Robot ini dikendali melalui interface di permukaan, melakukan manuver dengan sangat baik dengan bantuan 4 motor penggerak berkekuatan 1060 kv. Manipulator RJBA V.2015 mampu mengangkat beban mencapai 600 gram dengan diameter maksimal benda $8 \mathrm{~cm}$.

\section{Daftar Pustaka}

[1] St. Suwardi, "Mengungkapkan Misteri Laut dalam bersama ROV," KabarIndonesia, 2008.

[2] M.C. Fang, C.S. Hou, J.H. Luo, "On the motions of the underwater remotely operated vehicles with the umbilical cable effect," Ocean Engineering. 2006. 
[3] A.J. Woods, J.D. Penrose, A.J. Duncan, R. Koch, D. Clarck, "Improving The Operability of Remotely Operated Vehicles," The APPEA Journal, 1998.

[4] Norwegian Technology Centre, "Remotely Operated Vehicle (ROV) services," NORSOK standard U-102. Oslo, Norway, 2003.

[5] V. Rigaud, "Innovation and Operation with Robotized underwater Systems," Journal of Field robotics, 2007.

[6] NOAA, "Remotely Operated Vehicle (ROV)", 2010.

[7] E. Ahadyat, "Kontrol Manipulator Lengan Robot dengan Memperhitungkan Input Halangan," Bandung: Insitut Teknologi Bandung. 2008.

[8] H. A. Kusuma, "Rancang Bangun Mini Remotely Operated Vehicle (ROV) Untuk Eksplorasi Bawah Air," Bogor: Institut Pertanian Bogor, 2012.

[9] N. A. A. Putra, "Pengembangan Robot Jelajah Bawah Air (RJBA V.2014) untuk Eksplorasi Bawah Laut," Bogor: Institut Pertanian Bogor, 2014.
[10] J. Newman, B. Robinson, "Development of a dedicated ROV for a dedicated ROV for ocean science," MTS Journal, 1992.

[11] Atmel, "8-bit Atmel Microcontroller with 16/32/64KB In-System Programmable Flash," 2014.

[12] M. Idris, "Rancang Bangun dan Uji Kinerja Water Temperature Data Loger," Bogor: Institut Pertanian Bogor, 2014.

[13] A. Olejnik, "Visual identification of underwater objects using a ROV-type vehicles: "Graf Zeppelin" wreck investigation," Polish Maritime Research, 2008.

[14] R. D. Christ, L. W. Robert, "The ROV Manual : A User ide for Observation-Class Remotely Operated Vehicle," Elsevier Ltd. Oxford, 2007.

[15] S. H. Ismail, "Perancangan Program Pemilihan Propeller Jenis Wageningen B Series Berbasis Efisiensi," Surabaya: Institut Teknologi Sepuluh November, 2010.

[16] M. Haugen, "Modeling and Control of ROV Manipulators," Trondheim: Norwegian University of Science and Technology, 2012.

[17] R. D. Christ, L. W. Robert, "The ROV Manual Second Edition: A User Guide for Remotely Operated Vehicle," Elsevier Ltd. Oxford, 2013. 